\title{
A CONSTITUIÇÃO DO PADRÃO INTERACIONAL EM UM CURSO A DISTÂNCIA: MOVIMENTOS CRÍTICO-COLABORATIVOS
}

\author{
THE CONSTITUTION OF THE STANDARD INTERACTIONAL IN DISTANCE \\ EDUCATION : CRITICAL COLLABORATIVE MOVIMENTS
}

Wellington de Oliveira

Pontifícia Universidade Católica de São Paulo - LAEL

Faculdades Integradas Coração de Jesus

\begin{abstract}
Resumo
Os cursos de educação a distância têm características próprias e contam com as conquistas da tecnologia que permitem interações entre o aluno e o professor e entre alunos. $\mathrm{O}$ objetivo deste artigo é discutir o desenvolvimento crítico colaborativo dessas interações com vistas à compreensão do processo pedagógico reflexivo que se configura nesse espaço educativo. Os resultados mostram que a experiência de colaboração crítica aplicada em contexto virtual vivenciada no curso abriu perspectivas ao desenvolvimento de um processo pedagógico virtual plural, acolhedor da contradição estabelecida no diálogo entre os colaboradores como forma de avançar coletivamente, comprometido com a transformação, que se operacionaliza no movimento de um processo histórico e social.
\end{abstract}

Palavras-chave: Educação a distância. Padrão interacional. Novas tecnologias. Colaboração crítica.

\begin{abstract}
The courses of distance education have their own characteristics and feature the achievements of technology that allows interactions between the student and teacher and among students. The aim of this paper is to discuss the development of these critical collaborative interactions with a view to understanding the process of reflective taking shape in education area. The results show that the experience of critical collaboration applied in virtual context experienced in the course opened up the development of an educational process virtual plural, with contradictions in the dialogue established between pairs as a way to move forward collectively committed to transformation, which operationalizes the movement in a historical and social process.
\end{abstract}

Keywords: Distance education. Standard interaction. New Technologies. Critical collaboration.

\section{CONSIDERAÇÕES INICIAIS}

A questão central deste artigo é caracterizar como a colaboração crítica desenvolvida em contexto virtual de aprendizagem se constitui em um processo pedagógico, que gera um 
percurso de formação crítico-reflexiva no espaço de Educação a Distância. A fim de operacionalizar esse objetivo, buscarei respostas para a seguinte questão: Como a articulação do padrão interacional revela o movimento de construção da colaboração crítica?

Os dados para análise foram produzidos no período de 12 de março de 2008 a 30 de junho de 2008 e são fruto de um curso de formação de professores em contexto virtual, elaborado para alunos estagiários do curso de Pedagogia da Faculdade de São Bernardo - FASB, em São Bernardo do Campo, que envolveu o pesquisador e professor do curso, Wellington, e quatro alunos do curso de Pedagogia, Cristiane, Mário, Valdete e Pamela, todos nomes fictícios.

Em relação às técnicas de produção, foram utilizados os registros das interações síncronas gravadas automaticamente na ferramenta do sistema MSN e realizadas entre o pesquisador e os alunos por meio de chats. Para a realização da pesquisa, orientei-me pelo paradigma da pesquisa crítica com foco na colaboração, que exige um envolvimento ativo entre ações dos participantes.

Segundo Ibiapina (2003), a colaboração, como uma modalidade de condução de pesquisa, ganha espaço nos contextos de formação de professores devido ao destaque galgado pelas práticas discursivas entre pesquisador e pesquisado como ferramenta importante para a compreensão e transformação dos contextos escolares. Assim, no contexto desta pesquisa, tanto o pesquisador quanto os sujeitos envolvidos têm igual oportunidade de explorar suas experiências em relação aos discursos dos envolvidos, analisando, refletindo, criando e recriando novas possibilidades de fazer melhor aquilo que já fazemos.

Observo, ainda, que a pesquisa crítica de colaboração intercala-se com as necessidades e especificidades de cada contexto específico de investigação, o que torna os modos de pesquisa bastante flexíveis, a fim de refletir as questões significativas para os envolvidos na pesquisa.

Por fim, esta discussão que proponho insere-se na perspectiva das discussões sobre o ensino a distância que não se coloca apenas ao nível de uma mudança tecnológica, antes está associada também a uma mudança nas concepções dos professores sobre o modo como se aprende, à mudança das formas de interação entre quem aprende e quem ensina e à mudança do modo como se reflete sobre a natureza do conhecimento.

Essa nova e diferente possibilidade de ensino, embora represente uma realidade, contrapõese ao modelo de ensino que temos no paradigma vigente. Por isso mesmo, entendo e concordo com o pensamento de autores como Collins (2006), Tavares (2006) e Freire (2008), que sinalizam para essa questão observando que para se pensar a educação a distância são necessárias pesquisas e desenvolvimento de ações para a sua utilização na escola. Ações estas que têm o foco na formação do professor, constituindo-o para a criação de estratégias pedagógicas diferenciadas, modelos de aplicação e avaliação como suporte para ao processo de ensino e aprendizagem. 
Para discutir a questão da colaboração crítica desenvolvida em contexto virtual organizarei o artigo em duas partes. A primeira em que abordarei a questão teórica da orientação interlocutória e a segunda em que discutirei, com base nos dados, a constituição do padrão interacional alocêntrico, relacionando-o com teorias que me permitam compreender o seu desenvolvimento na perspectiva da colaboração crítica.

\title{
2 A ORIENTAÇÃO INTERLOCUTÓRIA
}

Com base em Quignard (2000), considero as orientações interlocutórias como espaços que são apresentados e percebidos pelos colaboradores, visto que a articulação dessa interação representa o resultado de um processo que marca a transformação. Logo, a orientação interlocutória especifica o papel do agente na/pela transformação. O autor aponta para a orientação interlocutória como uma transformação que especifica o lugar do sujeito na interação, a partir de uma relação triangular entre o locutor, o alocutário e o problema comum.

Segundo Quignard (2000, p.125):

\begin{abstract}
Nous relevons là un trait distinctif des actes de dialogue: ceux dont la transformation est autocentrée, pour lesquels l'agent de la transformation est le locuteur lui-même et ceux dont la transformation est allocentrée, pour lesquels l'agent pressenti est l'allocutaire. Le second critère de notre taxonomie est donc l'orientation interlocutoire de la transformation, qui spécifie la place de cette dernière dans la relation triangulaire entre le locuteur, l'allocutaire et le problème commun. ${ }^{1}$
\end{abstract}

Conforme o autor, essa alteridade pode ser marcada das seguintes formas: autocêntrica para a qual o agente da transformação é o próprio locutor; e alocêntrica - para qual o agente sentido é o destinatário.

Para Kerbrat-Orecchioni (2006), a interação é constituída por unidades dialogais, seus constituintes de maior dimensão, e unidades monologais, seus constituintes de menor dimensão. As unidades dialogais são assim chamadas, porque ocorrem sempre numa situação de interlocução. Enquanto as unidades monologais podem ser produzidas, mesmo numa situação de interação/interlocução, sem que o destinatário a elas reaja, verbal ou paraverbalmente. Ou seja, as unidades dialogais não existem sem as unidades monologais, mas estas podem existir sem aquelas. Kerbrat-Orecchioni (2006) propõe um modelo que simplifica a esquematização da comunicação verbal, que é constituído de dois pares: um emissor (locutor) e o outro receptor (alocutário) que trocam os papéis quando o emissor excursiona na recepção e o receptor se torna emitente em uma situação dialógica. “Cada um

\footnotetext{
1 Notamos aqui uma característica distintiva dos padrões enunciativos: aqueles cuja transformação é autocentrada, em que o agente da transformação é o próprio falante e aqueles cuja transformação é alocêntrica, em que o agente potencial é o ouvinte. O segundo critério de nossa taxonomia é a orientação interlocutória que marca a direção de urgência da transformação, em vez de especificá-la na relação triangular entre o orador, o ouvinte e o problema comum. (Tradução livre do autor do artigo.)
} 
dos dois pares são providos de expertises 'lingüística' (fala) e 'paralingüística' (gesto), de expertises 'culturais' e 'ideológicas' e 'determinações' que geram escolhas individuais que impulsionaram o universo da fala”. (KERBRAT-ORECHIONI, 2006, p.20).

Assim, observo que qualquer ato discursivo é sempre co-produzido, não só simplesmente porque é um ato que se sucede continuamente a outro em um enquadramento dialógico, mas também porque nas operações discursivas sequenciais entra em linha de conta a imagem que o locutor faz do alocutário, o que desencadeia constantes reformulações dos atos do discurso; logo, é ponto-chave que o papel de locutor é transferido de um participante a outro num continuum conversacional.

A materialidade dessa orientação interlocutória poderá ser analisada a partir da presença dos dêiticos pessoais, uma vez que, na determinação do uso das marcas de pessoa, fica estabelecida a relação dos sujeitos em relação ao enunciado.

Segundo Oliveira (2003, p.68), os elementos dêiticos têm uma função indicial de determinar a relação espaço-temporal do sujeito em relação a sua posição no discurso, ou seja, sua percepção se faz como modalizadora e contextualizadora das relações espaçotemporais nas construções discursivas dos enunciados. Ainda segundo esse autor, a dêixis pode ser percebida como um modalizador discursivo, ou seja, marcador pessoal do sujeito da enunciação e dos seus respectivos lugares no discurso, organizados no tempo da enunciação.

Basicamente, o locutor, no exercício do discurso, apropria-se das formas linguísticas, investindo-as de sentido, a fim de circunscrever-se como sujeito $(e u)$, que só poderá configurar a completude do seu dizer a partir da ressignificação de seu dito por outro (tu) atualizador.

A dêixis pessoal é representada predominantemente pelos pronomes pessoais como constituintes das expressões referenciais que aparecem na estrutura formal dos enunciados, ou seja, os interlocutores que se alternam na enunciação: primeira pessoa, aquela de quem parte o discurso; segunda pessoa, aquela a quem se dirige o discurso; e terceira pessoa, aquela sobre a qual é o discurso - fazendo referência à subjetividade na linguagem.

Oliveira (2003, p.68) aponta que:

Os pronomes pessoais eu e tu, dêiticos puros, instituem a comunicação de maneira necessária e suficiente entre locutor e alocutário, enquanto ele (s) e ela (s) mostram que a pessoa que denotam, não é nem o locutor, nem o alocutário, isto é, instituem-se como um não-alocutário que exige um antecedente linguistico para sua localização no discurso, configurando-se como dêiticos contextuais.

Todavia, os nomes próprios podem constituir-se como expressões dêiticas pessoais, uma vez que representam formas linguísticas que, assim como os dêiticos e as expressões definidas, apenas referem. Ou seja, referem pessoas, dizem delas, identificando-as. Eles 
indicam, apontam para certa pessoa, por necessidade de apelo, de descrição, ou como circunscrição a determinadas comunidades, identificam um indivíduo distinguem um indivíduo do outro.

\section{A CONSTITUIÇÃO DO PADRÃO INTERACIONAL NO CURSO A DISTÂNCIA}

Um exame geral dos excertos que analiso para discutir a interação nesse curso revela a dominância de um padrão interacional alocêntrico, ou seja, o agente cria no contexto da atividade condições para a inserção de outros na ação, para que se formulem perguntas, questionamentos, opiniões, façam julgamentos e avaliação. Essa participação alocêntrica ${ }^{2}$ gera uma espécie de contrato interacional em que as relações humanas se movem pela forma como os participantes ocupam seu lugar na interação e instituem suas formas de participação, distanciamento, aproximação, bem como uma alternância constante de turnos na articulação dos eventos comunicacionais na atividade. Essa questão pode ser observada no quadro a seguir.

\section{Excerto da aula 8: exemplo de constituição do padrão alocêntrico}

\begin{tabular}{c|l}
\hline W-AL & $\begin{array}{l}\text { Primeiro como vcs encaravam a experiência de um trabalho virtual antes } \\
\text { de participarem desse projeto? }\end{array}$ \\
\hline V-AL & $\begin{array}{l}\text { A principio não tinha a menor compreensão do que era uma aula virtual, } \\
\text { não acreditava muito por desconhecer...e também não tinha a noção de } \\
\text { interação do grupo }\end{array}$ \\
\hline C-AL & $\begin{array}{l}\text { (..) da forma como fazemos, eu ainda não havia participado, tão } \\
\text { regularmente, mas eu dou monitoria para alunos do Curso (...) da } \\
\text { Universidade Livre (...) em Santo André... tenho 3 alunos, mas } \\
\text { trabalhamos mais via email... }\end{array}$ \\
\hline W-AL & $\begin{array}{l}\text { depois que iniciamos... em que essa concepção de aula virtual mudou } \\
\text { para vocês? }\end{array}$ \\
\hline V-AC & $\begin{array}{l}\text { Para mim houve um grande crescimento, existe um interação, uma } \\
\text { parceria muito grande começo a lidar melhor com o instrumento } \\
\text { (computador) }\end{array}$ \\
\hline C- AC & $\begin{array}{l}\text { nisso concordo com a Val, é muito mais proximo, parece que não } \\
\text { conseguimos nos desconectar.. estamos sempre sintonizados na mesma } \\
\text { 2faixa...rsrsr se é q podemos dizer assim }\end{array}$ \\
\hline V-AC & $\begin{array}{l}\text { Para mim os nossos encontros têm rendido muitas leituras.. Está cada } \\
\text { vez mais prazeroso, em virtude da descontração de todos. }\end{array}$ \\
\hline
\end{tabular}

É possível notar que, nessa forma de participação dos interlocutores, ou seja, na interação, no momento em que o agente levanta alguma questão sobre o conteúdo temático, a partir da participação alocêntrica dos integrantes, na perspectiva de um contrato interacional, há uma necessidade de posicionamento dos demais participantes.

\footnotetext{
${ }^{2} \mathrm{Na}$ organização dos quadros que discutem o padrão interacional adotarei a inicial dos nomes de cada participante e as siglas AL - participação alocêntrica e AC - participação autocêntrica.
} 
Conforme Quignard (2000), a orientação interlocutória transforma e especifica o lugar do sujeito na interação, a partir de uma relação triangular entre o agente, o interlocutor e o seu problema comum. No caso em foco, o problema se configura a partir de uma necessidade do agente em discutir a experiência vivida no curso em contexto virtual; à proporção que as enunciações se colocam, os participantes são responsivos não só ao locutor, mas também às novas relações com o problema em discussão a partir de um questionamento. Há marcas dêiticas que revelam a forma como esse padrão interacional se constitui, como se pode observar no quadro seguinte.

Excerto da aula 6: exemplos do uso do nome próprio como forma de referenciação dêitica

\begin{tabular}{c|l}
\hline W-AL & $\begin{array}{l}\text { Tudo isso está previsto nesse comentário Pam? Além Mário..o qto? } \\
\text { Val....????? }\end{array}$ \\
\hline V-AL & $\begin{array}{l}\text { Wellington em sua atividade qual era o seu objetivo a alcançar é toda a } \\
\text { equipe jogando bem? }\end{array}$ \\
\hline M-AC & $\begin{array}{l}\text { Prof. penso que além do sentido, tem a ver com reflexão e ação em } \\
\text { cima do que nós acreditamos que é certo. Fazer apenas pela tarefa não } \\
\text { traz significado }\end{array}$ \\
\hline W-AL & $\begin{array}{l}\text { boa pergunta Val..eu não socilaizei o motivo como posso querer que vcs } \\
\text { discorram sobre ele..o sentido se fez parcialemnte..a partir do sentido } \\
\text { que essa atividade tem para vcs...o meu motivo era a colaboração e a } \\
\text { crítica reflexiva..o que de fato parece estar acontecendo..só que } \\
\text { precisamos falar mais entre nós. }\end{array}$ \\
\hline V-AC & $\begin{array}{l}\text { Wellington penso que o seu motivo de colaboração e a crítica reflexiva, } \\
\text { estamos caminhando para serem alcançados (...) }\end{array}$ \\
\hline
\end{tabular}

Aqui o padrão interacional alocêntrico revela-se linguisticamente no desenvolvimento dessas interações pelo uso da dêixis pessoal representada nos nomes próprios e nos pronomes e, por vezes, nas nomeações: professor, meninas, meninos, pessoal, galera etc, utilizados ao longo da interação para a garantia de uma aproximação entre o locutor e o interlocutor (como se pode observar nos exemplos: Queridos... muito obrigado por estarem comigo nesse projeto; Oi pessoal, tudo bem?; Gente, vamos organizar nosso pensamento.....K?).

Como aponta Kerbrat-Orecchioni (2006), o processo de nomeação se constitui por determinações semântico-enunciativas em virtude de se dar no interior de um processo social de identificação, que está diretamente vinculado à maneira como o sujeito vê o mundo, a realidade que o cerca. Ou seja, ao dar nome a qualquer coisa, ser e objeto, o homem reconhece o item nomeado como real, visto que não nomear, ou não ter nome, nada mais é que a não-existência.

Assim, o ato de nomear carrega dentro de si mesmo o movimento de uma história que o configura. Nesse sentido, os nomes interpelam e constituem a existência social do sujeito, ao mesmo tempo em que delimitam sua existência, pois definem o domínio do possível, do pensável, do executável - por exemplo, do gênero, da raça, da sexualidade e de tantas outras marcas de subjetividade. 
Percebo nessa enunciação que, por meio da estratégia de nomeação, o professor busca acolher os participantes, o que me leva a admitir com Kerbrat, amparada por Benveniste, que o sujeito (professor) se constitui em presença dos colaboradores. Conforme Bakhtin (2004), o sujeito toma a forma verbal a partir do ponto de vista do outro e, em definitivo, do ponto de vista do grupo a que pertence numa interação que o constitui, não sendo, então, concebido fora das relações que o ligam ao outro. Assim, o sujeito ao nomear-se, o faz porque já considera a possibilidade de uma relação colaborativa construída entre seus pares.

Percebo ainda que, nesse quadro, os pronomes pessoais são utilizados em menor proporção que os nomes próprios, o que de certa forma se justifica pela própria característica dos chats que propiciam um ambiente de maior envolvimento pessoal entre os participantes.

O uso do nome próprio aparece, também, como marca indicial da não-pessoa, por vezes, representada no corpus pelo pronome ele. Essa ocorrência linguística está presente, quando os sujeitos referem-se aos autores que compõem o quadro teórico da discussão. Segundo Oliveira (2003), a dêixis pode ser percebida como um modalizador discursivo, ou seja, marcador pessoal do sujeito da enunciação e dos seus respectivos lugares no discurso, organizados no tempo da enunciação.

Também o nome próprio revela a compreensão de como os interlocutores, ao se projetarem social e emocionalmente na atividade, permitem que uma maior aproximação se estabeleça entre os pares, o que possivelmente os encoraja na participação. Conforme KerbratOrecchioni (2000, p. 28), a interação é o lugar de uma atividade coletiva de produção de sentido, atividade que implica o emprego de negociações explícitas ou implícitas que podem ter êxito ou fracassar. Por isso, ao interagirem, os colaboradores negociam sentidos e posições, fazendo com que a colaboração crítica assuma, assim, um estatuto de ação no outro e sobre o outro.

Todavia, a interação não se constitui somente pelas formas de aproximação entre os interlocutores, antes ela se configura também pela maneira como as sequências de turnos são organizadas. O quadro a seguir mostra um excerto de quando os colaboradores se propõem a avaliar a experiência da aula virtual. Observo, na forma como se organizam esses turnos, que a regra do "fala um por vez" (KERBRAT-ORECCHIONI, 2006) não funciona exatamente como na conversação oral. Aqui se observa que eu estou digitando minha pergunta ao mesmo passo em que Pam ainda está discutindo algo. Nessa direção, amparado em Marcuschi e Xavier (2004), sinalizo que nas conversações virtuais é possível digitar uma resposta ao mesmo tempo em que outros participantes e um mesmo interlocutor receberem, em um único turno, várias respostas referentes a interações anteriores de uma variedade de outros interlocutores. Os turnos, assim, não seguem o padrão de alternância, pois é possível a um mesmo interlocutor falar por vários turnos e sobre assuntos diferentes. Além disso, pode acontecer da resposta de um ator, em um turno determinado, demorar em razão de o interlocutor ser desconectado do sistema, por exemplo. Tais fatos implicam pares que se relacionam entre si, mas que não estão necessariamente dispostos em uma sequência ordenada. 


\section{Excerto da aula 8: formas de organização do Padrão interacional alocêntrico}

\begin{tabular}{c|l}
\hline P- AL & $\begin{array}{l}\text { em relação as aulas virtuais, acredito que nós conseguimos ter mais } \\
\text { "liberdade" ao expor idéias... temos mais tempo para refletir sobre a fala do } \\
\text { outro.... elaborar o pensamento, além do que eu me sinto mais a vontade } \\
\text { utilizando o msn é verdade.... }\end{array}$ \\
\hline W- AL & $\begin{array}{l}\text { E a reflexão crítica? Como vcs encaram aquilo que discutimos como } \\
\text { reflexão no processo de formação de vcs? }\end{array}$ \\
\hline P- AC & $\begin{array}{l}\text { quando nos reunimos (presencial) as vezes me sinto como se não estivesse } \\
\text { lá, pq vcs conseguem discutir o assunto com a profundidade que eu ainda } \\
\text { não tenho }\end{array}$ \\
\hline V- AC & $\begin{array}{l}\text { Uma coisa eu tenho certeza, aprendi a ler e a refletir sobre o que eu leio } \\
\text { com o maior rapidez }\end{array}$ \\
\hline W-AL & $\begin{array}{l}\text { o grupo está bem entrosado e acredito que as leituras e discussões } \\
\text { ampliaram meus conhecimentos, mas ainda estou presa a conceitos... por } \\
\text { exemplo, quando vc prof propõe alguma atividade fico "engessando" meu } \\
\text { pensamento e reflexo disso são as minhas produções, me prendo a uma } \\
\text { única coisa }\end{array}$ \\
\hline P- AL & $\begin{array}{l}\text { qdo vc diz presa a conceitos..vc quer dizer que falta uma atitude prática de } \\
\text { colaboração..Pam? }\end{array}$ \\
\hline V-AL & $\begin{array}{l}\text { Eu não entendi o significado de conceito Pam, explica-se melhor fluir de } \\
\text { que forma... Falar o que vc acha que é certo, mas tem receio }\end{array}$ \\
\hline P- AC & $\begin{array}{l}\text { ao escrever sobre reflexão critica e colaboração me preocupei somente com } \\
\text { o significado, e não me vi em uma situação reflexiva, pois escrevi sobre } \\
\text { mas não estava praticando }\end{array}$ \\
\hline
\end{tabular}

Considero que, embora esse seja um grupo que já apresentava laços de convivência no desenvolvimento do curso, nas enunciações do quadro acima fica implícito um constrangimento pessoal, não pelo fato dos participantes não conseguirem interagir, mas pelo desafio que a atividade representava em sua consecução, devido ao domínio dos conceitos, o que aponta para uma provável articulação de um padrão interacional autocêntrico (centrado na fala do professor) nas primeiras aulas. É o desenvolvimento das formas de ouvir os interlocutores, o respeito pelos limites e dúvidas, as oportunidades de todos colocarem as necessidades construídas ao longo de seu desenvolvimento que tornam a atividade bastante desafiadora quanto ao objeto em discussão - colaboração crítica como revelado por um conjunto de sequências transacionais, por exemplo, a descrita acima.

Conforme Kerbrat-Orechioni (2000), as sequências transacionais constituem, por sua vez, o corpo da interação verbal (que pode ser constituído por uma só sequência transacional) e são, em geral, mais extensas e mais complexas, uma vez que nelas há, pelo menos, um tema de conversa, mais ou menos aceito pelos interlocutores, os quais, durante o tempo da interação, permanecem, regra geral, os mesmos, interagindo com foco em uma finalidade pragmática comum que se amplia à medida que a interação se desenvolve. Na sequência acima, por exemplo, quando Pam afirma que sua participação online é mais intensa do que no ambiente presencial, sua preocupação não é especificamente com a interação entre os pares, visto que nesse trecho sua participação marca-se intensamente, mas sim com a 
construção do objeto (a colaboração crítica), tanto na sua conceitualização como no seu uso prático, no caso o pensamento crítico e a reflexão crítica.

Essa participação de Pam revela que não só a participação alocêntrica constitui-se a partir de sequências que ampliam as possibilidades e formas de participação dos interlocutores no desenvolvimento do curso, mas também por uma reflexão que concentra o objeto e o instrumento em suas relações contextuais. O que a aluna discute sobre a participação online gera uma questão sobre as possibilidades de uso da ferramenta tecnológica como forma de proporcionar, no âmbito da atividade, uma forma de expansão para gerar novas competências e até mesmo aumentar a eficácia do ensino daquelas que já foram construídas. Isso porque os alunos se conscientizam à medida que se desenvolve uma perspectiva de criticidade com uso das novas ferramentas, pois conforme os sujeitos vão se apropriando das ferramentas do ambiente virtual, elas permitem que o aluno conheça a identidade do outro com quem estabelece uma comunicação, oportunizando que o conceito de impessoalidade perca espaço.

Conforme Freire (2008), a ação do meio digital sobre os indivíduos, mediada por ferramentas, práticas e linguagens singulares, aliada a uma ação crítico-reflexiva desses indivíduos sobre o meio e sobre os outros indivíduos, oportuniza a construção/coconstrução/desconstrução/reconstrução do conhecimento e a sua inserção crítica no mundo digital, como cidadãos geradores, guardiões e intérpretes de informações, que conduz a uma formação plena do eu como sujeito individual, social e tecnológico.

Embora o padrão interacional alocêntrico seja fortemente marcado pela alternância de turnos, característica pontual das ferramentas de interação síncrona, isso por si só não revela a colaboração crítica. Nas primeiras aulas, como já sinalizei, houve uma movimentação constante nos turnos conversacionais, mas o esquema de desenvolvimento desses turnos ainda está pautado pelo padrão autocêntrico em que o professor questiona e responde ao aluno e o aluno dirige uma resposta ou uma pergunta ao professor. Tomemos um excerto de aula presente no quadro seguinte. 
Excerto da aula 4: constituição do padrão alocêntrico por meio de questionamentos.

\begin{tabular}{|c|c|}
\hline W- AL & E ai...Leontiev? formação docente? quais as considerações? \\
\hline $\mathrm{V}-\mathrm{AC}$ & $\begin{array}{l}\text { Eu consigo enxergar o prof. alienado ou não a medida em que trabalha para } \\
\text { oferecer alguma coisa para a sociedade }\end{array}$ \\
\hline P- AC & $\begin{array}{l}\text { bom acredito que na formação de professores Leontiev cita a } \\
\text { apropriação cultural }\end{array}$ \\
\hline W-AC / AL & $\begin{array}{l}\text { Leontiev afirma que "a linguagem constitui o material básico de que dispõe } \\
\text { o homem para planear a sua atividade, e que nisso se manifesta a } \\
\text { capacidade ou função da linguagem como instrumento do } \\
\text { pensar”.(LEONTIEV, s/d, p.57, Daí nós pensarmos naquilo que } \\
\text { construímos quando formamos ou estamos em formação. } \\
\text { Val? O que vc acha? (...), é devido a essa função que em nós, seres } \\
\text { humanos, existe a auto-consciência que temos de nós mesmos enquanto } \\
\text { pessoas, e que podemos organizar conscientemente a nossa conduta.” } \\
\text { (LEONTIEV, s/d, p.57-58). Lembram do Vygotsky e o conceito de } \\
\text { linguagem interior? }\end{array}$ \\
\hline$P-A C$ & $\begin{array}{l}\text { a atividade humana se caracteriza pela adaptação do homem ao meio } \\
\text { para satisfação de suas necessidades, então a linguagem pode ser } \\
\text { entendida como reguladora de nossas ações(?) }\end{array}$ \\
\hline $\mathrm{W}-\mathrm{AL}$ & Conseguem ver a relação com Leontiev? \\
\hline $\mathrm{V}-\mathrm{AL}$ & A linguagem é o instrumento para se chegar a todos os resultados(?) \\
\hline W-AL & $\begin{array}{l}\text { Sim...Val..essa concepção é, inclusive, Vygostskiana, agora e a consciência } \\
\text { meninas? Considerando a perspectiva histórico-cultural, defende-se que a } \\
\text { consciência está em constante processo de formação como bem afirma } \\
\text { Leontiev (s/d, p.94): “a consciência é o reflexo da realidade, refratada } \\
\text { através do prisma das significações e dos conceitos lingüísticos elaborados } \\
\text { socialmente”. } \\
\text { E ai pessoal? Muita lenha na fogueira? }\end{array}$ \\
\hline V-AL & $\begin{array}{l}\text { Wellington a consciência faria o papel da linguagem seria ela um } \\
\text { instrumento na formação do professor(?) }\end{array}$ \\
\hline W- AL & $\begin{array}{l}\text { Não Val..a consciência é o resultado da ação do instrumento no processo de } \\
\text { formação... }\end{array}$ \\
\hline V-AL & é o que se busca(?) \\
\hline W- AL & $\begin{array}{l}\text { com certeza Val..é o resultado dessa ação..se pensarmos na formação..mas } \\
\text { tb é um processo de apropriação pontual daquilo que se tem como objetivo } \\
\text { no meio... }\end{array}$ \\
\hline
\end{tabular}

O professor cria espaços à participação dos alunos por meio de questionamentos diretos, entretanto, a natureza desses questionamentos estabelece condições para que os sujeitos participem dialeticamente com ele mas não entre eles, o que reaviva um esquema bilateral no contrato interacional estabelecido.

Kerbrat-Orecchioni (2000, p. 239-240) aponta que essas sequências são compostas por duas trocas verbais imbricadas: a intervenção reativa do alocutário, por um lado, fecha a 
primeira troca verbal do locutor e, por outro, abre uma segunda, a que uma nova intervenção do primeiro locutor, dessa vez reativa, põe termo.

Nesse excerto, vejo que a fala extensa do professor se faz necessária para que os demais interlocutores se inteirem do assunto, abordado anteriormente. Noto que as alunas Valdete e Pamela ainda não possuem o domínio de compreensão necessária para argumentarem sobre o conceito abordado, o que possivelmente impossibilita a troca de opiniões/informações que constituem a interação necessária para o construto das ideias. É possível verificar, também, que a orientação interlocutória das duas alunas, nesse momento, é notadamente autocêntrica, o que revela que para que haja colaboração crítica é preciso que os sujeitos tenham condições para organização das suas participações para então haver uma contribuição entre pares.

É o que assinala Ibiapina (2008, p. 18): colaboração não significa cooperação, tampouco participação; significa oportunidade igual e negociação de responsabilidades, em que os partícipes têm voz e vez. Ao que acrescento que esta voz e vez não se referem a um posicionamento no turno conversacional, mas a saberes que se constroem conjuntamente como forma de legar, ao outro, autonomia nas discussões. Não há colaboração pelo simples fato de legarmos ao outro a palavra. A palavra é uma forma de gerar a autonomia necessária ao desenvolvimento das ideias, portanto ela representa uma forma de inscrever ou reescrever nossa participação no mundo, com vistas a transformá-lo por significados de consciência.

Conforme Leontiev (1983), a palavra está presente nas formas básicas de desenvolvimento da atividade humana, inscreve-se na própria ação junto com o trabalho e é condição primordial sob influência da qual os homens se desenvolvem enquanto portadores dos movimentos conscientes e objetivos da realidade. Para o autor, o sujeito é o produto do desenvolvimento de suas atividades em meios nos quais ele interage. Entretanto, considero importante enfatizar que a atividade realizada não é a integralidade da atividade do sujeito, o real da atividade faz referência ao que não fazemos; que queremos fazer sem conseguir; que poderíamos ter feito e não fizemos; que fazemos sem fazer o que poderia ser feito.

É no desenvolvimento da atividade que o padrão interacional vai se constituindo de autocêntrico (voz de autoridade centrada no professor) para alocêntrico (voz de autoridade centrada nos colaboradores) em um movimento recursivo de uso da palavra. O que não quer dizer que ele se configure dicotomicamente como um ou outro padrão, mas a dominância ou não de um determinado padrão é reveladora dos movimentos de colaboração crítica que se desenvolvem na interação, conforme se observa no quadro seguinte. 


\section{Excerto da aula 5 : transformação do padrão interacional de autocêntrico para alocêntrico}

\begin{tabular}{c|l}
\hline W - AL & Vamos iniciar nossa discussão? Como vcs vêem a colaboração? \\
\hline V - AL & $\begin{array}{l}\text { Deu para entender bem o que é colaboração, pois ela não é ajuda... Então é } \\
\text { o que se vivencia no dia - a dia }\end{array}$ \\
\hline M - AL & Penso que a colaboração é uma forma de alcançar os objetivos... \\
\hline W - AL & $\begin{array}{l}\text { Exatamente Val..mas aquilo que se é construído no dia-a-dia em parceria, } \\
\text { com instrumentos reflexivos... }\end{array}$ \\
\hline C - AL & $\begin{array}{l}\text { quanto a questão da colaboração...... dá para refletir bastante até que ponto } \\
\text { podemos ir, onde estamos, e o que fazer... }\end{array}$ \\
\hline C - AL & $\begin{array}{l}\text { A colaboração é muito mais que uma reflexão , é a conscientização, é o } \\
\text { trabalho em equipe é justamente o que estamos fazendo }\end{array}$ \\
\hline W - AL & $\begin{array}{l}\text { Colaboração parece-me algo que o ser humano, esqueceu-se de fazer parte } \\
\text { integrante do seu processo de crescimento seja ele sócio-cultural-historico- } \\
\text { economico ou político. Todos estamos emaranhados uns aos outros de } \\
\text { alguma forma. O problema é justamente o que vemos no texto, o lado negro } \\
\text { do ser, o faz parecer maior do que é, projetando-se por meio de sombras, } \\
\text { para proteger-se de sabe-se lá o que. }\end{array}$ \\
\hline M,P,V,C - AL & $\begin{array}{l}\text { Proponho um exercício de colaboração: vamos refletir e responder juntos } \\
\text { algumas questões? o que vcs acham? }\end{array}$ \\
\hline W - AL & $\begin{array}{l}\text { legal, ok, tudo bem, ótimo... } \\
\text { beneficia? Como ela pode estar a serviço de uma educação transformadora? }\end{array}$ \\
\hline V - AC & a conscientização é a tomada de posição? \\
\hline P - AC & $\begin{array}{l}\text { acredito que a reflexão é pensar na ação... ela serve para orientar nossos } \\
\text { atos }\end{array}$ \\
\hline C - AC & $\begin{array}{l}\text { a meu ver. Reflexão, é voltar-se para dentro, é um tempo necessário para } \\
\text { colopcar as coisas em ordem em seu interior para podermos dar um passo a } \\
\text { frente... Beneficia inicialmente ao próprio interlocutor, irradiando ondas aos } \\
\text { que o rodeam. }\end{array}$ \\
\hline $\begin{array}{l}\text { partindo deste olhar interior, deste, replanejar de ações é que ela pode } \\
\text { influenciar uma educação transformadora }\end{array}$ \\
\hline $\begin{array}{l}\text { Reflexão é uma espécie de crítica e autocrítca. Ela beneficia toda a } \\
\text { comunidade, pois é nas diferenças de opinião que nós vemos onde estamos } \\
\text { falhando ... }\end{array}$ \\
\hline
\end{tabular}

O padrão interacional se modifica quando eu (professor) altero minhas intervenções. Ao modificar meu padrão interacional, abandono as perguntas que são meramente interativas e garantem apenas a participação social em detrimento de um conjunto de perguntas que questionam implicações e consequências, pontos de vista e perspectivas. Vejo essa diferenciação nas formas de perguntar do professor como um traço distintivo entre conversa e discussão crítica. Para Dillon (1994), a conversa difere da discussão em todos os aspectos menos no fato das pessoas falarem umas com as outras. Na conversa, não existe um objetivo definido, qualquer pessoa pode falar sobre quase tudo o que desejar e pode fazê-lo sempre que o desejar, todavia, a discussão é disciplinada, tem um objetivo bem definido e centra-se num tópico específico. 
Assim, à proporção que modifico minhas formas de perguntas conduzo os colaboradores a refletirem sobre a questão proposta, a partir do exame de diferentes interpretações, fatos, sugestões, opiniões, perspectivas, experiências, de forma a construírem coletivamente uma nova apreciação, que resultará na legitimação de sua participação crítico-colaborativa. A escolha da discussão como veículo de aprendizagem, no entendimento de Dillon (1994), reflete a importância da autonomia intelectual e da colaboração social, visto que os sujeitos constroem os seus instrumentos sócio-cognitivos a partir da acumulação e interiorização de experiências e progridem intelectualmente por meio das interações com outros indivíduos. A discussão alarga o nível de compreensão individual pelo contato com as interpretações e a experiência construída pelos outros na sala de aula e, segundo Brookfield, S. e Preskill, S. (1999), implica respeito pelas vozes e experiências de todos os participantes, à medida que contribui para a aprendizagem dos processos e convenções do discurso democrático.

Nesse excerto, começo a preparar o ambiente para o desenvolvimento crítico colaborativo, uma vez que o que realmente produz essa transformação não é a pergunta, nem a resposta, mas o ambiente em que as perguntas e respostas são consideradas, um ambiente que se cria a partir da práxis.

Observo que, nas primeiras aulas do curso, minha postura é muito centrada na viabilidade da atividade que é ensinar o conteúdo programado para o curso. Isso se dá, pois segundo Heller (2004), na vida cotidiana, os pensamentos e as ações são muito mais determinados por sua funcionalidade imediata do que por razões de ordem teórica ou filosófica. Ao redimensionar sua forma de agir, com vistas à produção de colaboração crítica, o professor prossegue na realização de uma atividade cotidiana (ensinar o conteúdo). Todavia, elevando-a ao nível de uma mediação teórica, reflexiva, crítica e aprofundada, que tende a eliminar uma forma comum de determinação utilitária direta entre o que se faz e se pensa na cotidianidade do processo de ensino e aprendizagem. De acordo com Heller (2004), ao exercício de reflexão sobre nossas ações cotidianas atribui-se o nome de práxis, que é o oposto das ações pragmáticas. A práxis significa a realização de atividades humanogenéricas (comuns a todos os homens, como o trabalho) de forma consciente. Para a autora, isso se relaciona à capacidade do intelectual em estabelecer a mediação de uma teoria a respeito do objeto de trabalho e de uma teoria sobre o próprio trabalho, processo este que se consolida pelo conhecimento e ação no processo educativo, a partir da reflexão do cotidiano na práxis.

Se o ambiente encoraja a formulação de perguntas como uma atividade importante em si mesma e se propicia uma forma para que os sujeitos tratem as perguntas e respostas como oportunidades de investigação, estabelece-se uma relação crítico-colaborativa (Wellington me fala quem é o multiplicador dentro da escola?, mas o conflito gera colaboração?, a conscientização é a tomada de posição?, essas leituras sobre a formação de prof. tem nos levado a uma reflexão?), como aponta Magalhães (2007, p.54), o discurso do professor por meio do trabalho conjunto revela o processo de construção do conhecimento. A fala, que inicialmente refletia julgamento de valores com base em ações não refletidas, passa a revelar tentativas de entender suas ações e os processos que têm lugar em sua sala, e de 
introduzir mudanças no diálogo da sala-de-aula, e um crescente autocontrole na tomada de decisões.

No uso dessa estratégia de pergunt(A)cão, os participantes exercitam a colaboração crítica em uma ação que se quer prática, uma vez que "a práxis é elevada à condição de fundamento de toda a relação humana, a relação prática sujeito-objeto no plano do conhecimento tem que se inserir no próprio horizonte da prática” (MARX, 1983a, p. 149). Essa colaboração desenvolvida na atividade rompe com o senso comum do praticismo, em que se age com vistas a uma prática sem teoria ou com um mínimo dela. Como pontua Gâmboa (1995, p.33), “o pragmatismo infere que o verdadeiro se reduz ao útil e solapa a própria essência do conhecimento”.

À proporção que se modifica o padrão interacional dos participantes, vejo um exercício de colaboração que migra de uma ação subjetiva e responsiva destinada a satisfazer os interesses individuais (professor ensina o conteúdo/ alunos aprendem) para uma ação material, objetiva, que se constitui na atividade a partir de um interesse social de transformação do espaço educativo que se configura (professor e alunos aprendem na apreensão dos movimentos de um pensamento crítico). Essa reorganização do padrão interacional favorece o espaço de colaboração crítica, uma vez que se manifesta e se transforma graças às tensões estabelecidas entre os colaboradores. Como focaliza Gâmboa (1995, p. 33), apoiado em Vasquez, a práxis é o fundamento do mundo em que hoje nos desenvolvemos, e por ser justamente o fundamento do mundo real que hoje existe, a práxis proporciona à ciência, ao conhecimento, não só a sua finalidade como o seu objeto. $\mathrm{O}$ conhecimento não é mera contemplação, à margem da prática; consequentemente, o conhecimento só existe na prática.

Esse processo de mudança na forma de agir estabelece uma contradição, que se revela à medida que o professor deixa de ser o centro do processo para construir colaborativamente com os alunos, ao mesmo passo que os alunos deixam de ser só responsivos ao professor e tomam consciência de que sua participação movimenta e transforma a aula em um "espaço em que se pode agir criticamente e questionar no sentido de pensar o mundo, e não ser pensado por ele” (KONDER, 2001, p. 20.). Os colaboradores, ao questionarem, fazem suposições, inferências e implicações, mostrando-se engajados no desenvolvimento da atividade, revelando que refletir sobre, e avaliar o raciocínio e as estratégias de participação do outro é um indicador de um movimento de mediação que, segundo Aguiar e Ozella (2004, p. 225), possibilita a utilização, a intervenção de um elemento/um processo, em uma relação que antes era vista como direta, permitindo-nos pensar em objetos/processos ausentes até então.

O que parece constituir, então, o padrão interacional alocêntrico na atividade é essa movimentação dialética que muda o direcionamento do contrato interacional, tornando a interação que se estabelece na atividade mais complexa à proporção que os colaboradores se constituem perguntadores e avaliadores das questões tratadas pelo professor. Nas palavras de Quignard (2000), essa orientação interlocutória se dá como uma transformação que especifica o lugar do sujeito na interação, a partir de uma relação triangular entre o 
locutor, o alocutário e o problema comum, sendo que em sua forma alocêntrica os interesses e atenções estão centralizados no desenvolvimento do outro.

Esse movimento dialético no padrão interacional alocêntrico marca possiblidades transformadoras no discurso que criam contexto para o sujeito clarificar a si e a outros sua compreensão, interpretação ou conhecimento da realidade. Como aponta Bakhtin (2004), o discurso é uma unidade real, delimitada pela alternância dos sujeitos, na qual a individualidade se estabelece em relação aos demais discursos pela posição do enunciador e com os quais mantém uma atitude responsiva ativa (concordância, discordância, obediência, execução, objeção, adesão etc).

Nessas circunstâncias, o padrão interacional alocêntrico, constituído nesse curso, é fruto da interação caracterizada entre os colaboradores por uma dimensão discursiva mediada pela colaboração crítica, por meio da qual se forjam os processos de significação nos enunciados. Os colaboradores se constituem na atividade e revelam em suas expressões a historicidade e as condições de produção dos seus discursos, uma vez que, ao questionarem, lançam mão dos conhecimentos construídos e revelam as nuances das suas transformações de ações e pensamentos, conforme apontam os excertos das participações de Mário (aula 5) e Valdete (aula 8) nos quadros seguintes.

Excerto da aula 5: participação de Mário como constituição da colaboração crítica

\begin{tabular}{l|l}
\hline \multirow{2}{*}{ W - AL } & $\begin{array}{l}\text { Na visão de vocês ...o que é reflexão? Para que ela serve? A quem } \\
\text { beneficia? Como ela pode estar a serviço de uma educação } \\
\text { transformadora? }\end{array}$ \\
\hline \multirow{3}{*}{ M - AC } & $\begin{array}{l}\text { Refletir/ação é isso aí. Parece simples mas não é. Isto só é possível se vc } \\
\text { estiver com a mente aberta a novas idéias. É desta forma que eu vejo na } \\
\text { ICC, pois são muitos conceitos que eu, particularmente, tenho que } \\
\text { primeiramente conhecer, para depois refletir sobre a minha ação } \\
\text { dentro da ICC. }\end{array}$ \\
\hline
\end{tabular}

Excerto da aula 8: participação de Val como constituição da colaboração crítica

\begin{tabular}{c|l}
\hline W- AL & $\begin{array}{l}\text { Primeiro como vcs encaravam a experiência de um trabalho virtual antes } \\
\text { de participarem desse projeto? }\end{array}$ \\
\hline V-AL & $\begin{array}{l}\text { A principio não tinha a menor compreensão do que era uma aula } \\
\text { virtual, não acreditava muitopor desconhecer... e também não tinha a } \\
\text { noção de interação do grupo }\end{array}$ \\
\hline W-AL & $\begin{array}{l}\text { depois que iniciamos...em que essa concepção de aula virtual mudou para } \\
\text { vocês? }\end{array}$ \\
\hline V-AC & $\begin{array}{l}\text { Para mim houve um grande crescimento, existe um interação, uma } \\
\text { parceria muito grandecomeço a lidar melhor com o } \\
\text { instrumento(computador) }\end{array}$ \\
\hline
\end{tabular}

Os exemplos acima parecem revelar que a possibilidade de interagir sem a preocupação de expressar o que aprendeu permite que os colaboradores exponham suas ideias e ansiedades e possam encontrar um contexto para deixar aflorar a sua subjetividade. O contexto criado 
pela qualidade da participação na atividade possibilita que os colaboradores sejam transformados de várias as formas - pessoal, social, cognitiva e afetiva - na relação com o outro. Em outras palavras, as relações construídas em um padrão interacional alocêntrico parecem servir de estímulo a essas transformações, favorecendo trocas colaborativas que se estabelecem nas discussões.

De fato, os excertos citados parecem revelar que o desenvolvimento de um padrão interacional alocêntrico oportunizou espaço para que as condições objetivas se alterassem, à medida que se alteravam também as condições subjetivas. Isto é, a atividade revela-se como o lugar de uma experiência constitutiva do $e u$, podendo ser objeto de transformações que contribuem para o desenvolvimento da ação reintegrada como manifestação exterior de outra atividade ou de novas relações sociais, pois, como postula Lopes (2003, p. 37) apoiada em Vygotsky, cada sujeito não é só expressão de sua individualidade, mas também de sua coletividade, uma vez que o eu só se reproduz nas relações de interação com os demais.

O desenvolvimento dos participantes, inclusive a forma de se colocarem nos turnos, está intrinsecamente atrelado a essa dinâmica pessoal, o que de certo modo me faz perceber que a motivação não é específica de uma atividade. Antes, é estabelecida pelo sujeito uma configuração única de significados que participa da produção de sentido de uma atividade concreta, mas que não é alheia às outras significações produzidas de forma simultânea em outras esferas de vida dos sujeitos. Segundo Rey (2003), as subjetividades - social e individual - atuam na qualidade de constituintes e constituídos do outro e pelo outro. $\mathrm{O}$ sujeito que aprende expressa a subjetividade social dos diferentes espaços sociais em que vive no processo de aprender, visto que nenhuma atividade humana resulta numa atividade isolada do conjunto de sentidos que caracterizam o mundo histórico e social da pessoa.

\section{CONSIDERAÇÕES FINAIS}

O conjunto dos dados, de uma forma geral, revela que a produção discursiva pressupõe a existência de um sujeito produtor que se inscreve num enunciado diretamente com a ajuda do significante $e u$. Entretanto, aqui no caso dos dados apresentados, percebo que o eu foi substituído pelo uso do nome próprio, o que marca uma forma de significação no enunciado em outros termos, pois os nomes próprios, quando empregados como expressões referenciais, identificam os seus referentes, não os descrevendo em termos de uma propriedade relevante que o nome denota, mas utilizando a associação única e arbitrária entre um nome próprio e o seu portador (LYONS, 1977, p. 176).

A partir daqui, entendo que o sistema de referenciação dêitica não é o único a que as línguas naturais recorrem, mas é o mais importante e, sem dúvida, o mais original, pois essa referenciação tem a particularidade de se efetuar não na relação com outras unidades internas do discurso, mas diretamente com os dados concretos da situação de comunicação e, mais precisamente, em relação ao nome próprio, cuja enunciação vocativa é considerada 
como uma forma de interpelação virtual que só pode aparecer numa relação entre um enunciado e suas circunstâncias de enunciação (GRANGER, 1982, p. 36).

Contudo, é fundamental lembrar que a estratégia interacional utilizada pelos participantes (referência direta pelo nome próprio) não existe de forma isolada, antes se articula a outros elementos como, por exemplo, pronomes pessoais, saudações e elogios, que produzem na interação efeitos de dialogicidade e comprometimento entre os participantes.

Em relação ao padrão interacional constituído no curso, não se pode dizer que há exclusividade em seu desenvolvimento, isto é, há momentos no curso, mais precisamente nas aulas inicias, em que ele se configura mais autocêntrico, e outros, como é o caso dos excertos das aulas finais que analisei, em que ele se configura alocêntrico. Essa configuração alocêntrica aponta que a centralidade dos turnos não está marcada pelo aluno ou pelo professor, antes é conduzida de forma a assegurar que cada um dos participantes construa uma forma de participação em equilíbrio com os demais, minimizando as ocorrências assimétricas no desenvolvimento desses turnos.

A observância de um padrão alocêntrico sinaliza para um complexo processo de negociação, visto que, como aponta Magalhães (2004), colaborar é oportunizar voz a todos os participantes, para colocarem suas experiências, compreensões e suas relações de discordâncias em relação aos discursos dos outros parceiros.

À proporção que os sujeitos acionam sua participação linguística e abrem uma perspectiva alocêntrica que exige do outro uma participação, a atividade se modifica e a linguagem deixa de ser apenas um meio de expressão para se tornar organizadora de estratégias interacionais. Conforme avançam em sua participação alocêntrica, os sujeitos envolvem-se e originam novos propósitos de interação e, por conseguinte, novos propósitos sociais, uma vez que a sala de aula virtual é um local em que os sujeitos (professor, alunos e tutores) constroem ativamente um sentido do mundo, atrelando-o aos objetivos que desejam estabelecer.

\section{REFERÊNCIAS}

BROOKFIELD, S.; PRESKILL, S. Discussion as a way of teaching: Tools and techniques for democratic classrooms. San Francisco: Jossey-Bass Publishers, 1999.

COLLINS, H.; CELANI, M. A. A. Critical Thinking in Reflective Sessions and in Online Interactions. In: RAJAGOPALAN, K. (Org.). Applied Linguistics in Latin America. New York: John Benjamins Pub Co, 2006.

DILLON, J. Using discussion in classrooms. Buckingham: Open University Press, 1994. 
FREIRE, M. M. A formação tecnológica de professores: refletindo, problematizando, buscando. II ENCONTRO CAPES-MECD/DGU, Linguagem, Educação e Virtualidade. UNESP/Araraquara, 2008.

FREIRE, M. M.; RAMOS, R. C. G. Curso de leitura instrumental via rede: da preparação à concretização. In: COLLINS, H.; FERREIRA, A. (Orgs.). Relatos de experiência de ensino e aprendizagem de línguas na Internet. Campinas: Mercado de Letras, 2004, p. 279-295.

GRANGER, G. A quoi servent les noms propres. Langage, [S.l.] n. 66, p. 21-36, 1982.

HELLER, A. O cotidiano e a história. 4. ed. São Paulo: Paz e Terra, 2004.

IBIAPINA, I. M. L. de M. Formação de professores. Texto e Contexto. Autêntica: Belo Horizonte, 2008.

KERBRAT-ORECCHIONI, C. Análise da conversação. Princípios e Métodos. São Paulo: Parábola, 2006.

. Les genres de l'oral: Types d'interactions et types d'activités. In: Journée

d'études: les genres de l'oral (Université Lumière - Lyon 2, 18.04.03), 2003. http://gric.univ_lyon2.fr/Equipe1/actes/journées-genre.htm . (acesso em 08 de 2006)

LEONTIEV, A. O desenvolvimento do psiquismo. Lisboa: Livros Horizonte, 1983.

LYONS, J. Semântica I. Lisboa: Presença; São Paulo: Martins Fontes, 1977.

MAGALHÃES, M. C. C. A pesquisa colaborativa e a formação do professor. In: FIDALGO, S.; SHIMOURA, A. (Orgs.). A pesquisa crítica de colaboração. Um percurso na formação docente. São Paulo: Ductor, 2007.

MARCUSCHI, L. A. Gêneros textuais emergentes no contexto da tecnologia digital. In: MARCUSCHI, L. A.; XAVIER, A. C. (Orgs.). Hipertexto e gêneros digitais. Rio de Janeiro: Lucerna, 2004, p. 13-67.

MARX, K. O Capital: crítica da economia política. Livro primeiro, Tomo I. Tradução Regis Barbosa e Flávio R. Kothe. São Paulo: Abril Cultural, 1983a.

1983b.

Contribuição à critica da economia política. São Paulo: Martins Fontes, Manuscritos econômico-filosóficos. In: MARX, K. Manuscritos econômicofilosóficos e outros textos escolhidos. 5. ed. São Paulo: Nova Cultural, 1983c. (Coleção Os Pensadores). 
MARX, K.; ENGELS, F. A ideologia alemã (Feuerbach). São Paulo: Hucitec, 1996.

OLIVEIRA, W. de. A colaboração crítica no desenvolvimento de uma atividade de formação de professores a distância. Tese de Doutorado. São Paulo: Pontifícia Universidade Católica de São Paulo, 2009.

De dêiticos a fóricos: um estudo dos pronomes demonstrativos em Língua Portuguesa nos séculos XIX e XX. Dissertação de Mestrado. São Paulo: Pontifícia Universidade Católica de São Paulo, 2003.

QUIGNARD, M. Modélisation cognitive de l'argumentation dialoguée: étude de dialogues d'élèves en résolution de problème de sciences physiques. Thèse de doctorat de sciences cognitives. Grenoble: Université Joseph Fourier, 2000.

SÁNCHEZ-VÁSQUEZ, A. Filosofia da Práxis. São Paulo: Paz e Terra, 2007.

TAVARES, K. C. A. Aprender a moderar lista de discussão: a perspectiva da teoria da atividade. Tese de Doutorado. São Paulo: Pontifícia Universidade Católica de São Paulo, 2006. 